\title{
Suppressed Serum Prolactin Levels under Topical Treatment with Isoretinoin
}

\author{
Florian Brackmann*, Daniela Osinski, Helmuth-Günther Dörr, Regina Trollmann \\ Department of Pediatrics, University Hospital of Erlangen, Erlangen, Germany \\ *florian.brackmann@uk-erlangen.de
}

\begin{abstract}
Retinoids, with isoretinoin as one of its main representatives, are widely used in acne therapy for their effects on different mechanism of acne pathophysiology. Adverse effects of isotretinoin are well defined being the major limiting factor for its usage. Mucocutanous changes, teratogenicity as well as psychiatric and endocrinological side effects have been reported especially for systemic use. We report - for the first time endocrinological changes with suppressed prolactin levels after topical isoretinoin treatment in a patient who was originally examined for neurological symptoms.
\end{abstract}

Keywords: Isoretinoin, retinoids, acne, adverse effects, endocrinology

\section{INTRODUCTION}

Retinoids are derivatives of vitamin A which are used in acne therapy for many years. Isoretinoin as its main representative is used topically and systemically. Although retinoid effects on different parts of acne pathophysiology (epidermal proliferation, comedogenesis, sebum production, inflammation) are observed, its mode of action has not been elucidated yet. Adverse effects of isotretinoin are well defined being the major limiting factor for its usage. Next to mucocutanous changes, teratogenicity as well as psychiatric and endocrinological side effects have been reported [1].

\section{CASE Report}

A 15 year old adolescent male was admitted to our neuropediatric out-patient clinic for pathologic double vision. The patient reported to have double vision when focusing distant objects for more than 2 years. Looking at close objects and reading were not limited. No other neurological symptoms were reported. Approximately one year before this presentation an extensive diagnostic workup for the same symptoms had shown no organic pathological results. Laboratory infectious parameters, acetylcholine receptor antibodies, cerebral MRI and visual evoked potentials (VEP) were normal. Cerebral spinal fluid (CSF) diagnostics showed positive oligoclonal bands (CSF positive/serum negative) and no other pathology. Specifically, antibodies for Borrelia burgdorferi were not detected. At the time of presentation ophthalmologists reported about progressive abduction deficits in both eyes and requested an up to date exclusion of an underlying neurological disease. The patient presented in good clinical condition. He reported about subjective double vision when focusing distant objects and no other neurological symptoms. He negated continuous medication. No pupilloor oculomotor alterations as well as no otherwise motor or sensory deficits were present. Tendon reflexes were normal and symmetric. VEP showed normal latencies. Auxological parameters were in normal range (height $173.5 \mathrm{~cm}$, weight $65.4 \mathrm{~kg}$ ) with a mean genetic target height of $173.5 \mathrm{~cm}$. His Tanner stage was G5 with testicular volume sizes of $20 \mathrm{ml}$. The adolescent suffered from severe acne papulopustulosa for almost 5 years. Again, other neurological deficits, laboratory signs of infections and autoimmune etiologies were ruled out.

A Cerebral Magnetic Resonance Imaging (MRI) scan showed a small signal void of $7 \times 5 \mathrm{~mm}$ size in the pituitary gland after application of intravenous contrast. Therefore, a microadenoma was suspected. Endocrinological data showed normal hormone values for fT4 $(12.0 \mathrm{pg} / \mathrm{ml})$, TSH $(1.59$ $\mu \mathrm{U} / \mathrm{ml})$, testosterone $(2.58 \mathrm{ng} / \mathrm{ml})$, morning cortisol $(101 \mathrm{ng} / \mathrm{ml})$, FSH $(1.8 \mathrm{mU} / \mathrm{ml})$, IGF1 (328 $\mathrm{ng} / \mathrm{ml}$ ), and IGFBP3 $(4.2 \mu \mathrm{g} / \mathrm{ml}$ ). However, serum prolactin level was low with $0.5 \mathrm{ng} / \mathrm{ml}$ (normal range $4.7-16.6 \mathrm{ng} / \mathrm{ml}$ ). In the meantime, a second specific MRI-scan ruled out any pituitary anomaly as did all other clinical endocrinological examinations. 
In scrutiny for an explanation for the low prolactin levels, the patient was reassessed and reported for the first time about topical treatment with isoretinoin crème for his facial acne. He used isotrex crème (isoretinoin $0.05 \%$ ) for 12 months daily on his face, neck and upper thorax without sufficient efficacy. An underlying neurological condition could be excluded and double vision was corrected by strabismus surgery.

\section{DISCUSSION}

Several studies have reported effects of aromatic retinoids on pituitary hormone levels. Karadag et al. showed a decrease in TSH, LH, morning cortisol, ACTH and prolactin in 47 acne patients after short term (3 months) oral isoretinoin treatment [2]. The same group confirmed these effects in a larger sample of patients and was able to show that these effects are dose dependent and reversible [3]. Others found similar results [4-5]. Since at least IGF-related changes are parallel to acne progression these effects might be part of the working mechanism in acne therapy [3]. It is well known that changes of serum prolactin levels are linked with the dopaminergic system. Hyperprolactinemia induced by antipsychotic drugs such as risperidone is caused by dopamine D2 receptor antagonists [6]. It has been demonstrated that retinoids are able to induce the transcription of the dopamine receptor type 2 (D2R) gene in cultured pituitary cells, this effect being due to the presence of a functional retinoic acid response element in the D2R promoter [7]. The decrease in the levels of prolactin following isoretinoin treatment may therefore be related to an increase in central dopaminergic tonus [2]. All of these studies mentioned investigated endocrinological effects of oral retinoid treatment. For topical retinoid treatment a low systemic bioavailability $(<1 \%)$ after a single dose with increasing bioavailability after continuous treatment (up to 5.3\%) was shown in a group of patients with psoriasis [8]. Experimental data suggests that percutaneous absorption rate is affected by state of the skin barrier, retinoid type, vehicle and dose [9]. To the best of our knowledge systemic effects of topical retinoid treatment and isoretinoid treatment in particular have not been systemically investigated yet.

We report - for the first time - systemic endocrinological changes after topical treatment with isoretinoin. In our opinion duration and intensity of topical treatment together with severe impairment of the skin barrier due to poorly controlled acne papulopustulosa lead to systemic uptake and effects of isoretinoin treatment. We suggested to pauseisoretinoin treatment, but the patient refused our request in fear of a deterioration of his dermatological condition. We cannot currently define the longterm consequences of low serum prolactin levels for our patient, but recently it was shown that low prolactin levels were associated with reduced ejaculate and seminal vesicle volume in infertile men, and low prolactin was identified as an independent predictor of the incidence of major adverse cardiovascular events [10].

\section{CONCLUSION}

Our report is a reminder that topical medication has to be considered when side effects or indistinct laboratory results pose questions to the clinician. It further turns attention to the fact that topical retinoid treatment may be accompanied by systemic effects on the dopaminergic system causing low prolactin levels.

\section{REFERENCES}

[1] Zouboulis, C.C. and V. Bettoli, Management of severe acne. Br J Dermatol, 2015. 172 Suppl 1: p.27-36.

[2] Karadag, A.S., et al., Isotretinoin influences pituitary hormone levels in acne patients. ActaDermVenereol, 2011. 91(1): p. 31-4.

[3] Karadag, A.S., et al., The effect of different doses of isotretinoin on pituitary hormones. Dermatology, 2015. 230(4): p. 354-9.

[4] Angioni, A.R., et al., Effects of chronic retinoid administration on pituitary function. J Endocrinol Invest, 2005. 28(11): p. 961-4.

[5] Masood, M.Q. and H. Hakeem, Isotretinoin associated reversible hypothyroidism. Thyroid, 2011.21(9): p. 1039-40.

[6] Wieck, A. and P.M. Haddad, Antipsychotic-induced hyperprolactinaemia in women: pathophysiology, severity and consequences. Selective literature review. Br J Psychiatry, 2003. 182: p. 199-204. 
[7] Samad, T.A., et al., Regulation of dopaminergic pathways by retinoids: activation of the D2 receptor promoter by members of the retinoic acid receptor-retinoid $\mathrm{X}$ receptor family. ProcNatlAcadSci U S A, 1997. 94(26): p. 14349-54.

[8] Tang-Liu, D.D., R.M. Matsumoto, and J.I. Usansky, Clinical pharmacokinetics and drug metabolism of tazarotene: a novel topical treatment for acne and psoriasis. ClinPharmacokinet, 1999. 37(4): p. 273-87.

[9] Lehman, P.A., J.T. Slattery, and T.J. Franz, Percutaneous absorption of retinoids: influence of vehicle, light exposure, and dose. J Invest Dermatol, 1988. 91(1): p. 56-61.

[10] Rastrelli, G., G. Corona, and M. Maggi, The role of prolactin in andrology: what is new? RevEndocrMetabDisord, 2015. 16(3): p. 233-48. 